\title{
Interobserver agreement in the singh classification and spotorno criteria, and its relevance in cementing stem decision making
}

\begin{abstract}
Introduction: Hip fractures represent a public health problem worldwide, with 300,000 new cases every year. An important part of these patients will need a hip arthroplasty as a definitive treatment. One of the controversial topics is whether to use a cemented or uncemented stem. Spotorno et al. established criteria for this decision. However, one of the parameters is the Singh Classification, has a low interobserver reliability. The purpose of this study is to learn Spotorno's and Singh's interobserver agreement and how it affects the decision to cement the stem.

Methodology: 100 cases of hip fractures were presented to two observers, which assigned scores using the Spotorno's criteria and Singh's classification. Decision to use a cemented or uncemented stem was recorded according to Spotorno's recommendations. Interobserver agreement was measured using Cohen's kappa.

Results: Of the 100 cases, $67 \%$ were females and $33 \%$ were males, with a mean age of 74.9 years. Cohen's kappa for Singh's classification was 0.089 (slight agreement), and 0.317 for Spotorno's criteria (fair agreement). Both observers assigned the decision to use cemented stem in 99 cases, and 1 case with questionable indication, with an almost perfect agreement.

Conclusion: Even though Spotorno's criteria and Singh's classification have low interobserver agreement, it doesn't seem to affect the decision making for using cemented or uncemented stems in patients with hip fractures. More studies are necessary to confirm this situation in patients undergoing hip arthroplasty due to other causes.
\end{abstract}

Volume 5 Issue 6 - 2018

\author{
Soto González Luz María,' García Ortiz \\ Uriel Nahum, ${ }^{2}$ Quiroz William Jorge, ${ }^{3}$ Roque \\ Ruiz Omar Iván ${ }^{4}$ \\ 'Resident of Orthopaedic Surgery, UMAE Dr.Victorio de la \\ Fuente Narváez Hospital, Mexico \\ 2Department of Orthopaedic Surgery, General Zone Hospital \\ No. 3, Mexico \\ ${ }^{3}$ Department of Health Investigation, UMAE Dr.Victorio de la \\ Fuente Narváez Hospital, Mexico \\ ${ }^{4}$ Department of Hip, Pelvis and Acetabulum surgery, UMAE Dr \\ Victorio de la Fuente Narváez Hospital, Mexico
}

\begin{abstract}
Correspondence: García Ortiz Uriel Nahum, Department of Orthopaedic Surgery, General Zone Hospital No. 3,Av. Colector 15 S/N Esq. Av, Instituto Politécnico Nacional. Col. Magdalena de las Salinas, Gustavo A. Madero, Zip Code 07760, Mexico City, Mexico, Tel +52I (55)57473500,

Email urielngercia@hotmail.com
\end{abstract}

Received: August 28, 2018 | Published: November 16, 2018

Keywords: spotorno criteria, singh classfication, hip fracture, hip arthroplasty, cemented hip arthroplasty, uncemented hip arthroplasty, interobserver agreement

\section{Introduction}

Hip fractures represent a public health problem worldwide, which is taking more importance every day. In the USA, hip fractures have an incidence of 300,000 new cases every year. ${ }^{1}$ Most of the patients affected are 50 years or older, with a mean age of 80 . The vast majority of patients are women, accounting for approximately $80 \%$ of cases. ${ }^{2,3}$ It has been observed that $50 \%$ of patients that were independent before a hip fracture won't be able to return to its previous life style, an $10 \%$ will be uncapable to return to their previous residence. ${ }^{2}$ It has also been noted an increase in patient's morbidity, as well as an increase of $36 \%$ in mortality per year.

An important group among hip fractures are those affecting the femoral neck, due to the high risk of femoral head necrosis. In these cases, hip arthroplasty has become the gold standard in treatment. In the USA approximately 100,000 hip arthroplasties are performed due to hip fractures. ${ }^{2,3}$ One of the controversial topics when performing a hip arthroplasty is the decision of using a cemented or uncemented stem.

In 1985, Spotorno et al designed the CLS femoral stem, and established specific criteria for decision making between using a cemented or uncemented stem. The decision was based in 4 clinical and radiographic parameters (age, sex, morpho-cortical index, and Singh stages). ${ }^{4,5}$ The Singh stages were proposed in 1970 as a way of staging osteoporosis with the use of hip radiographs. ${ }^{6}$ However, studies have observed that this classification does not correlate with bone mineral density measured with other methodologies. ${ }^{7,8}$ It has also been demonstrated that Singh stages have a low interobserver reliability, with a kappa index as low as $0.07 . .^{9-11}$ This situation can affect the final score assigned by the Spotorno criteria, and thus affecting the final decision of using cemented or uncemented stem. The objective of this study is to learn the interobserver agreement of the Singh stages and Spotorno criteria, and how it affects the decision making of using cemented or uncemented stem.

\section{Methodology}

We selected 100 random patients, with the diagnosis of hip fractures who were treated in the hip, pelvis and acetabulum department in the UMAE Dr. Victorio de la Fuente Narváez hospital. Patients with anteroposterior radiographs of both hips, with a complete record were selected. Patients with bilateral hip fractures, those with previous surgery of any of the hips, and those without a complete record were excluded.

The 100 cases were presented to two independent observers, who assigned a Singh stage and Spotorno score to the healthy hip. The table used by the observers to assign the stage and score can be found in Table $1 \&$ Figure 1 . The scores assigned by the observers were recorded, and statistical analysis with central tendency measures, Cohen's kappa for Singh stages and Spotorno score was done. According to the Spotorno score obtained, the decision of using a cemented or uncemented stem was assigned using the original recommendations by Spotorno et al. ${ }^{4}$ Finally, interobserver agreement for the decision of using a cemented or uncemented stem was measured. 
Table I Spotorno's criteria ${ }^{4}$

\begin{tabular}{ll}
\hline \multicolumn{2}{l}{ Parameter No. I:Age } \\
\hline Points Allocated \\
>70 years: & 4 points \\
6I-70 years: & 2 points \\
5I-60 years: & I point \\
<50 years: & 0 Points \\
\hline & \\
Parameter No. 2: Gender \\
Points Allocated \\
Women: $\quad 0$ points \\
Men:
\end{tabular}

\begin{tabular}{|c|c|}
\hline \multicolumn{2}{|c|}{ Parameter No. 3: Osteoporosis } \\
\hline Severe (Singh I-2): & 4 points \\
\hline Moderate (Singh 3-4): & 2 points \\
\hline Slight (Singh 5-6) & I point \\
\hline Physiological (Singh 7): & 0 Points \\
\hline \multicolumn{2}{|c|}{$\begin{array}{l}\text { Parameter No. 4:The anatomy of the } \\
\text { femur }\end{array}$} \\
\hline \multicolumn{2}{|c|}{ The point score of the $\mathrm{MCl}$} \\
\hline $\mathrm{MCl} \leq 2.2:$ & 4 points \\
\hline $\mathrm{MCl}>2.3:$ & 2 points \\
\hline $\mathrm{MCl}>2.7:$ & I point \\
\hline $\mathrm{MCl} \geq 3.0:$ & 0 Points \\
\hline \multicolumn{2}{|l|}{ Final assessment } \\
\hline $0-4$ points: & Cementless stem \\
\hline 5 points: & Questionable indication \\
\hline$\geq 6$ points: & Cemented stem \\
\hline
\end{tabular}

\section{Results}

Of the 100 selected patients, $67 \%$ were females and $33 \%$ were males. The mean age of the patients was 74.9 years \pm 14.6 , ranging from 23 to 98 years old. About the comorbidities, 34\% had diabetes, $26 \%$ hypertension, $27 \%$ had no comorbidities, and $13 \%$ had other comorbidities.

The record for the assigned Singh stages of both observers can be seen in Table 2. We obtained an interobserver agreement with Cohen's kappa of 0.089 for Singh's stages, which interprets as a slight agreement. Interobserver agreement for Spotorno's criteria was 0.317 , which interprets as a fair agreement. After assigning the surgical decision for both observers using Spotorno's criteria, both observers assigned to use a cemented stem in 99 cases, and 1 case with a questionable indication, obtaining an almost perfect agreement.

\section{Discussion}

Hip fractures represent a public health problem worldwide, with an incidence in the USA of 300,000 new cases yearly. Epidemiologic studies have reported a mayor prevalence of this pathology in female patients, with a mean age of 80 years. In our study, of all the cases we found a mean age of 74.9 years, which is very close to the one reported by other authors. ${ }^{2,3}$ Female sex was the most affected with $67 \%$, leaving males sex with $33 \%$, which agrees to some degree with other authors, but with a lesser percentage to that reported in other articles $(80 \%))^{2,3} 73 \%$ of our patients had comorbidities, being Diabetes Mellitus the most common (34\%), being followed by hypertension (26\%).

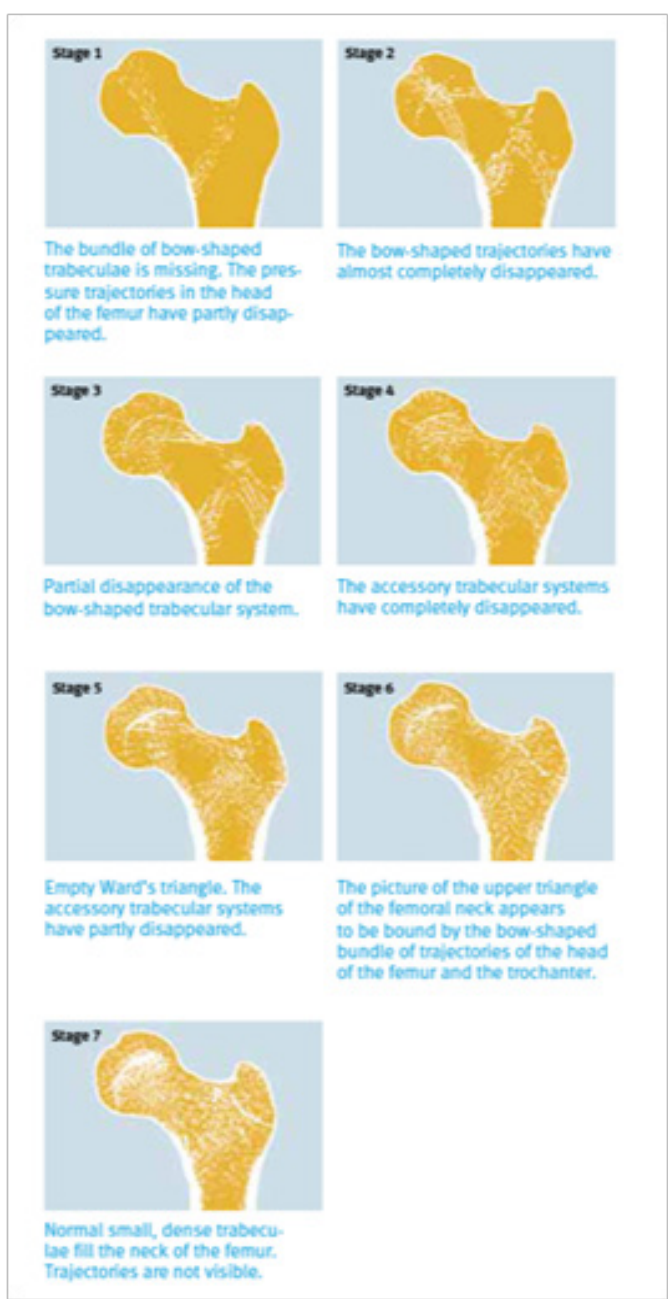

Figure I Singh's classification. ${ }^{6}$

Table 2 Distribution of Singh stages for both observers

\begin{tabular}{lll}
\hline Singh stage & Observer I & Observer 2 \\
\hline 1 & 0 & 20 \\
2 & 9 & 23 \\
3 & 42 & 35 \\
4 & 35 & 12 \\
5 & 14 & 8 \\
6 & 0 & 2 \\
7 & 0 & 0 \\
\hline
\end{tabular}


Of all the patients with hip fractures, an important number will require a hip arthroplasty as a definitive treatment, becoming necessary to take the decision of using a cemented or uncemented arthroplasty. Spotorno's criteria have become a fundamental guide for this decision making. However, one of the criteria is based in a subjective measurement. Singh's stages were proposed in 1970 as a parameter to measure patient's bone quality. Multiple studies have been done to measure Singh's stages interobserver agreement, reporting a kappa index of approximately $0.07 . .^{9-11}$ In our study, we obtained a Cohen's kappa of 0.089 , which is very close to that reported by other authors. ${ }^{9-11}$ Thus, we agree with other authors that Singh's stages do not allow to assess bone quality in patients with hip fracture.

Multiples studies have reported excellent results with the use of the Spotorno stem..$^{5,12-14}$ However, no study has measured interobserver agreement of the Spotorno's criteria for cementing the stem up to this date. In our study, after measuring interobserver agreement for the Spotorno's criteria, we obtained a kappa index of 0.317 , which translate as a fair agreement. We believe Singh's stages is the criteria producing a low kappa index value for the Spotorno's criteria.

At the time of assessing interobserver agreement for the decision making of cementing the stem, we found both observers agreed in cementing 99 of the cases, with an almost perfect agreement. Thus, according to this study, the poor interobserver agreement observed in the Spotorno's criteria and Singh's stages does not seem to affect the final decision making of cementing the stem in patients with hip fractures. It is important to mention that, according to other articles, ${ }^{2,3}$ most of the patients with hip fracture have characteristics that will assign high scores according to Spotorno's criteria (females with a mean age of 80 years). It is possible that, due to this situation, the final decision in our study was not modified despite the poor interobserver agreement for the Spotorno's criteria and Singh's stages. More studies are necessary where the interobserver agreement for the Spotorno's criteria and cementing decision are measured in patients undergoing total hip arthroplasty due to causes different to hip fracture. It is equally important to mention the final decision for cementing also depends of other factors, like comorbidities and surgeon's preferences. Thus, it is advisable to make other studies comparing the recommendations by the Spotorno's criteria with the surgeon's final decision for using a cemented or uncementd stem.

\section{Conclusion}

Even though the Spotorno's criteria have been widely used for the decision-making in cementing the femoral stem, we found a low interobserver agreement while using them. This is the result of the low interobserver agreement seen in the Singh's stages, which has been very well reported in other articles. Despite this fact, final decisionmaking is not affected in patients with hip fracture. However, more studies measuring interobserver agreement in patients undergoing total hip arthroplasty for other causes are necessary. It is advisable to use complimentary criteria to assess bone quality in patients undergoing hip arthroplasty.

\section{Funding details}

No funding received for this article.

\section{Acknowledgements}

None.

\section{Conflict of interest}

The author declares that there is no conflict of interest.

\section{References}

1. Brunner LC, Eshilian-Oates L, Kuo TY, et al. Hip Fractures in Adults. Am Fam Physician. 2009;67(3):537-542.

2. Siletz A, Childers CP, Faltermeier C, et al. Surgical Technical Evidence Review of Hip Fracture Surgery Conducted for the AHRQ Safety Program for Improving Surgical Care and Recovery. Geriatr Orthop Surg Rehabil. 2018;9:1-11.

3. Iannello P, Biassoni F, Bertola L, et al. The role of autobiographical storytelling during rehabilitation among hip-fracture geriatric patients. Eur J Psychol. 2018;14(2):424-443.

4. Spotorno L, Romagnoli S, Ivaldo N, et al. The CLS system. Theoretical concept and results. Acta Orthop Belg. 1993;59(1):144-148.

5. de Witte PB, Brand R, Vermeer HW, et al. Mid-Term Results of Total Hip Arthroplasty with the CementLess Spotorno (CLS) System. J Bone Joint Surg Am. 2011;93(13):1249-1255.

6. Singh M, Nagrath A, Maini P. Changes in trabecular pattern of the upper end of the femur as an index of osteoporosis. J Bone Jt Surg Am. $1970 ; 52(3): 457-467$.

7. Klatte TO, Vettorazzi E, Beckmann J, et al. The Singh Index does not correlate with bone mineral density (BMD) measured with dual energy X-ray absorptiometry (DXA) or peripheral quantitative computed tomography (pQCT). Arch Orthop Trauma Surg. 2015;135(5):645-650.

8. Salamat MR, Rostampour N, Zofaghari SJ, et al. Comparison of Singh index accuracy and dual energy X-ray absorptiometry bone mineral density measurement for evaluating osteoporosis. Iran $J$ Radiat Res. 2010;8(2):123-128

9. Qadir RI, Bukhari SI, Hospital NG. Singh's index accuracy with dexa scan for osteoporosis. KMC. 2016;24(1):12-15.

10. Faruk Ö, Md K, Proksimal Y, et al. Prediction of Osteoporosis through Radiographic Assessment of Proximal Femoral Morphology and Texture in Elderly; is it Valid and Reliable? Turkish J Osteoporos. 2015;21:46-52.

11. Exhibit S, Kapishnikov A, Pervushkin SS, Applications-detection C. Texture analysis of radiographic trabecular patterns for prediction of osteoporotic femoral neck fracture. 2014;1-10.

12. Yamasaki T, Yasunaga $Y$, Mori R, et al. The Cementless Spotorno stem in THA: 10 year results. HIP Int. 2014;24(1):98-102.

13. Müller LA, Wenger N, Schramm M, et al. Seventeen-year survival of the cementless CLS Spotorno stem. Arch Orthop Trauma Surg. 2010;130(2):269-275.

14. Evola FR, Evola G, Graceffa A, et al. Performance of the CLS Spotorno uncemented stem in the third decade after implantation. Bone Joint $J$. 2014;96-B(4):455-461. 